\title{
Efficacy of oat bran (Avena sativa $L$.) in comparison with atorvastatin in treatment of hypercholesterolemia in albino rat liver.
}

\author{
Maisaa M. AL-Rawi \\ Biology Department, Girls College, Makkah, Saudi Arabia.
}

\begin{abstract}
Introduction: The present study deals with the effect of oat bran (Avena sativa L.) in the treatment of hypercholesterolemia in comparison with a hypocholesterolemic drug, atorvastatin, on hypercholesterolemic liver in male albino rats.

Material and Methods: For this purpose four groups of rats (each containing 6 rats) were used. The first group was used as a control, the second was cholesterol-fed group with cholesterol $(0.5 \% \mathrm{w} / \mathrm{w})$ for 6 weeks. The third group was oats-fed hypercholesterolemic rats on oat supplemented diet $(20 \% \mathrm{w} / \mathrm{w})$ for 4 weeks and the forth group was atorvastatin-treated hypercholesterolemic rats orally at a dose of $0.18 \mathrm{mg} / \mathrm{Kg}$ body weight/day for 4 weeks.

Results: The biochemical results revealed a significant increase in serum LDL-C and a significant decrease in HDL-C level. In addition the activity of AST was increased in cholesterol-fed rats. Meanwhile, the treatment with oat soluble fiber or atorvastatin drug improved the above mentioned parameters. The histopathological examination of liver sections of cholesterol-fed group showed accumulation of lipid. Hepatocytes showed ballooning degeneration and manifested clear necrotic signs. Inflammatory cellular infiltration was found around the blood vessels, mild fibrosis near the portal blood vessels. However, liver impairment was reduced markedly in the liver of oat soluble fiber fed rats rather than atorvastatin drug treated rats.

Conclusion: The present study, however, confirms that the cereal grain oat may have potent beneficial health effects in reducing LDL cholesterol and should be included in the prudent diet of individuals with hyperlipidemia.
\end{abstract}

Keywords: liver, histopathology, oat bran, atorvastatin, hypercholesterolemia

\section{Introduction}

The Oat (Avena sativa) is a species of cereal grain, and the seeds of this plant, are used for food for people and animals, especially poultry and horses (Anderson et al., 1990). Oat is the only cereal containing a globulin or legume-like protein, avenalins, as the major $(80 \%)$ storage protein. Globulins are characterized by water solubility; because of this property, oats may be turned into milk but not into bread. The more typical cereal proteins, such as gluten and prolamines. The minor protein of oat is a prolamine: avenin. Oat protein is nearly equivalent in quality to soy protein which has been shown by the World Health Organization to be the equal to meat, milk, and egg protein. The protein content of the hull-less oat kernel (groat) ranges from 12 24\%, the highest among cereals (Asp et al., 1983).
Oats, an important source of water-soluble fibers, have long been recognized as a potential cholesterol-lowering dietary component (Davidson et al.,1991). Indeed, Ripsin et al. (1992) concluded from a metaanalysis of 12 trials that soluble fiber from oat products had a significant effect on total cholesterol concentrations. It was estimated that a daily consumption of $\approx 3 \mathrm{~g}$ soluble fiber lowered total cholesterol by 0.13 $\mathrm{mmol} / \mathrm{L}$ in normocholesterolemic persons and by $0.41 \mathrm{mmol} / \mathrm{L}$ in hypercholesterolemic persons (Brown et al., 1999).

The beneficial effects of oat products on the lipoprotein profile are ascribed to their soluble fiber compound, B-glucan (Braaten et al., 1994). B-glucan from oats is a nonstarch polysaccharide that is composed of $B-(1 \rightarrow 4)$-linked glucose units, which are separated every $2-3$ units by a 
single $B-(1 \rightarrow 3)$-linked glucose unit (Bell et al.,1999). B-glucan from barley (Bourdon et al.,1999) or yeast (Nicolosi et al.,1999) has also been shown to be hypocholesterolemic.

On 21 January 1997, the US Food and Drug Administration (FDA,1996) approved the printing on food-product packages of a health claim that "a diet high in soluble fiber from whole oats (oat bran, oatmeal and oat flour) and low in saturated fat and cholesterol may reduce the risk of heart disease". In its proposal, the FDA reviewed 37 studies in which oats were consumed as hot and cold cereals or used in a variety of other foods, eg, muffins, breads, shakes, and entrées.

Hypercholesterolemia is an established major risk factor for coronary artery disease. Lifestyle modification is the preferable form of treatment for most types of hyperlipidemia. Cholesterol metabolism is determined by diet, genetics, cholesterol absorption, and sterol synthesis and excretion (Anderson et al., 1990). The synthesis and excretion of bile acids is the major pathway of elimination of cholesterol. Primary bile acids are synthesized from cholesterol in the liver, and considered to catalyze the rate-limiting step in the biosynthesis process (Cohen, 1999). Hepatic bile acid synthesis is controlled in the liver through negative and positive feedback mechanisms. The consequences of increased bile acid excretion are stimulated cholesterol uptake from the circulation (Grundy et al., 1971; Reihner et al., 1990) followed by a decreased serum cholesterol concentration (Miettinen, 1979).

Oat bran has been shown to decrease serum cholesterol (Ripsin et al.,1992; Brown et al.,1999). Consumption of a diet rich in soluble fiber including oat bran (Jenkins et al., 1993) or of a diet supplemented with oat bran (Kirby et al.,1981; Anderson et al.,1984; Marlett et al.,1994) has been shown to increase fecal excretion of bile acids.

Atorvastatin is the preferred clinical lipid-regulating drugs (Li et al., 2003), it can effectively regulate blood lipids abnormal delay atherosclerosis progress in reducing clinical cardiovascular events in patients with hyperlipidemia (Chenhanyao, 2006). Atorvastatin has been shown not only to significantly lower LDL cholesterol levels (range $-41 \%$ to $-61 \%$ ) in a dosedependent manner in hypercholesterolemic patients (Nawrocki et al., 1995) but also to reduce plasma triglyceride levels by up to $46 \%$ in hypertriglyceridemic patients in the presence or absence of elevated LDL cholesterol concentrations (Bakker-Arkema et al.,1996; Alaupovic et al., 1997)

Because of the lack of sufficient reports on the histological effects of oat for treating hypercholesterolemia. The aim of this study was to investigate the cholesterol lowering efficacy of the dietary oats in comparison with a hypocholesterolemic drug, atorvastatin, on hypercholesterolemic liver in male albino rats.

\section{Material and methods}

\section{1-Chemicals}

Cholesterol, atorvastatin and oats were used in the present study. Cholesterol was supplied from Sigma Chemical Co. (ST. Louis MO). Atorvastatin was purchased from the Egyptian International Pharmaceutical Industries Company (10th of Ramadan city, Egypt) in the form of tablets. Oats were obtained from Nahrain Company for food industries Cairo-Egypt, and prepared in powder form and given to rats in their diet.

\section{2-Animals and design of the experiment}

Male albino rats (Rattus rattus) weighing about 140-160 $\mathrm{g}$ were used in the present study.

\section{Rats were divided into four groups as} follows:-

Group 1: Normal untreated control group. This group was fed on standard diet and supplied with water ad libitum.

Group 2: Cholesterol-fed group. The rats were fed on a normal diet supplemented with cholesterol $(0.5 \% \mathrm{w} / \mathrm{w})$ for 2 weeks to induce hypercholesterolemia (Moussavi et al., 1989), then continued to receive the cholesterol-supplemented diet for further 4 weeks.

Group 3: Oats-fed hypercholesterolemic group. Rats were fed on cholesterolsuppl-emented diet $(0.5 \% \mathrm{w} / \mathrm{w})$ for 2 weeks to induce hypercholeste- 
rolemia and given oats-supplemented diet $(20 \% \quad \mathrm{w} / \mathrm{w})$ (Jacobs, 1983) besides the same diet of cholesterol for another 4 weeks.

Group 4: Atorvastatin-treated hypercholesterolemic group. Rats were fed on a cholesterol-supplemented diet $(0.5$ $\% \mathrm{w} / \mathrm{w})$ for 2 weeks to induce hypercholesterolemia and given orally atorvastatin at a dose of 0.18 $\mathrm{mg} / \mathrm{Kg}$ body weight /day (Guerin et al., 2000) besides the same diet of cholesterol for another 4 weeks

\section{3- Histological examination}

For histological examinations, small pieces of the liver were immediately fixed in $10 \%$ neutral formalin solution, dehydrated in a graded series of alcohol, cleared in xylol and mounted in molten paraplast at $56-60^{\circ} \mathrm{c}$ and cut at $5 \mu \mathrm{m}$ on rotary microtome. The paraffin sections were stained with haematoxylin and eosin for histological studies and examined under light Leitz microscope.

\section{4- Statistical analysis:}

Means and standard deviations were calculated for each group and data were analyzed using Student's t-test (Snedecor and Cochran, 1967). The conventional level of $5 \%$ was taken as the level of significance.

\section{Results}

Feeding on a diet enriched with cholesterol for 6 weeks caused a significant increase in serum LDL-C level, while a significant decrease in HDL-C was recorded. In addition, the activity of AST was increased in cholesterol-fed rats. Meanwhile, the treatment with oat soluble fiber or atorvastatin drug improved the above mentioned parameters (Table1).

Concerning histological examination of the liver, sections of liver of control rats were formed of hepatic lobules, each lobule is made up of radiating plates. Strands of cells are forming a network around a central vein. The liver strands are altering with narrow sinusoids. These sinusoids have irregular boundaries composed of only a single layer of fenestrated endothelial cells and large irregularly phagocytic cells, which are known as Kupffer cells. Outside the hepatic lobule at certain angles, lie the portal areas of connective tissue each including a hepatic portal vein, a branch of hepatic artery and a bile ductile (Fig.1).

Liver sections of rats of cholesterolfed group showed general impairment of the normal structural organization of hepatic lobules in many areas. Cord-like arrangement of the normal hepatocytes not well distinct (Fig. 2). Appearance of fatty change was manifested by accumulation of lipid in form of large cytoplasmic vacuoles within some hepatocytes displacing the nucleus to one side. Hepatocytes showed hydropic degeneration, swollen and vacuolated cells. The sinusoidal spaces were somewhat dilated, Kupffer cells appeared swollen. Most of the hepatocytes manifested clear necrotic signs, some nuclei revealed clear signs of pyknosis (Fig. 3). Inflammatory cellular infiltration was found around the blood vessels, mild fibrosis near the portal blood vessels (Fig. 4).

Liver sections of rats of group 3 exhibited a normal pattern of liver parenchyma; with markable reduction in fatty droplets and decrease in sinusoidal dilatation (Fig. 5). Less inflammation and less fibrosis in the portal area were noticed (Fig. 6). i.e. reversed towards control sections were considerably higher.

The effect of treatment with atorvastatin in liver sections of rats of group 4 showed less improvement in histological structure comparing with section of rat liver of group 3, pronounced in normalized appearance of liver lobules and hepatocytes. The hepatocytes exhibited reduction in fat accumulation, less inflammation and less fibrosis (Fig. 7), less necrotic cells were also observed (Fig. 8). 
Efficacy of oat bran (Avena sativa L.) in.............

Table (1): Effect of treatment with oat and atorvastatin on serum LDL, HDL and AST of hypercholesterolemic rats.

\begin{tabular}{|c|c|c|c|c|}
\hline$\underbrace{\text { Treatment }}_{\text {Pavements }}$ & Control & $\begin{array}{c}\text { cholesterol-fed } \\
\text { rats }\end{array}$ & $\begin{array}{l}\text { Oats-fed } \\
\text { rats }\end{array}$ & $\begin{array}{c}\text { Atorvastatin- } \\
\text { treated rats }\end{array}$ \\
\hline $\begin{array}{l}\text { LDL-c } \\
\text { (mg/dl) }\end{array}$ & $27.2 \pm 2.02$ & $\begin{array}{c}121.3 \pm 1.96 \\
S^{a}\end{array}$ & $\begin{array}{c}33.1 \pm 1.6 \\
S^{a \& b}\end{array}$ & $\begin{array}{c}52.0 \pm 1.5 \\
\mathrm{~S}^{\mathrm{a} \& \mathrm{~b}}\end{array}$ \\
\hline $\begin{array}{l}\text { HDL-c } \\
\text { (mg/dl) }\end{array}$ & $41.2 \pm 1.3$ & $\begin{array}{c}19.4 \pm 0.91 \\
S^{a}\end{array}$ & $\begin{array}{c}38.3 \pm 0.62 \\
S^{\text {a\&b }}\end{array}$ & $\begin{array}{c}30.4 \pm 0.69 \\
S^{a \& b}\end{array}$ \\
\hline $\begin{array}{l}\text { AST } \\
(\mathbf{U} / \mathbf{L})\end{array}$ & $38.6 \pm 1.2$ & $\begin{array}{c}50.8 \pm 0.89 \\
S^{a}\end{array}$ & $\begin{array}{c}43.1 \pm 0.66 \\
S^{a \& b}\end{array}$ & $\begin{array}{c}40.95 \pm 1.00 \\
S^{a \& b}\end{array}$ \\
\hline
\end{tabular}

Values are expressed as means + SD. of six rats.

$\left(\mathrm{S}^{\mathrm{a}}\right)$ Significant at $\mathrm{P}<0.05$ as compared to control

$\left(\mathrm{S}^{\mathrm{b}}\right)$ Significant at $\mathrm{P}<0.05$ as compared to cholesterol-fed rats group 

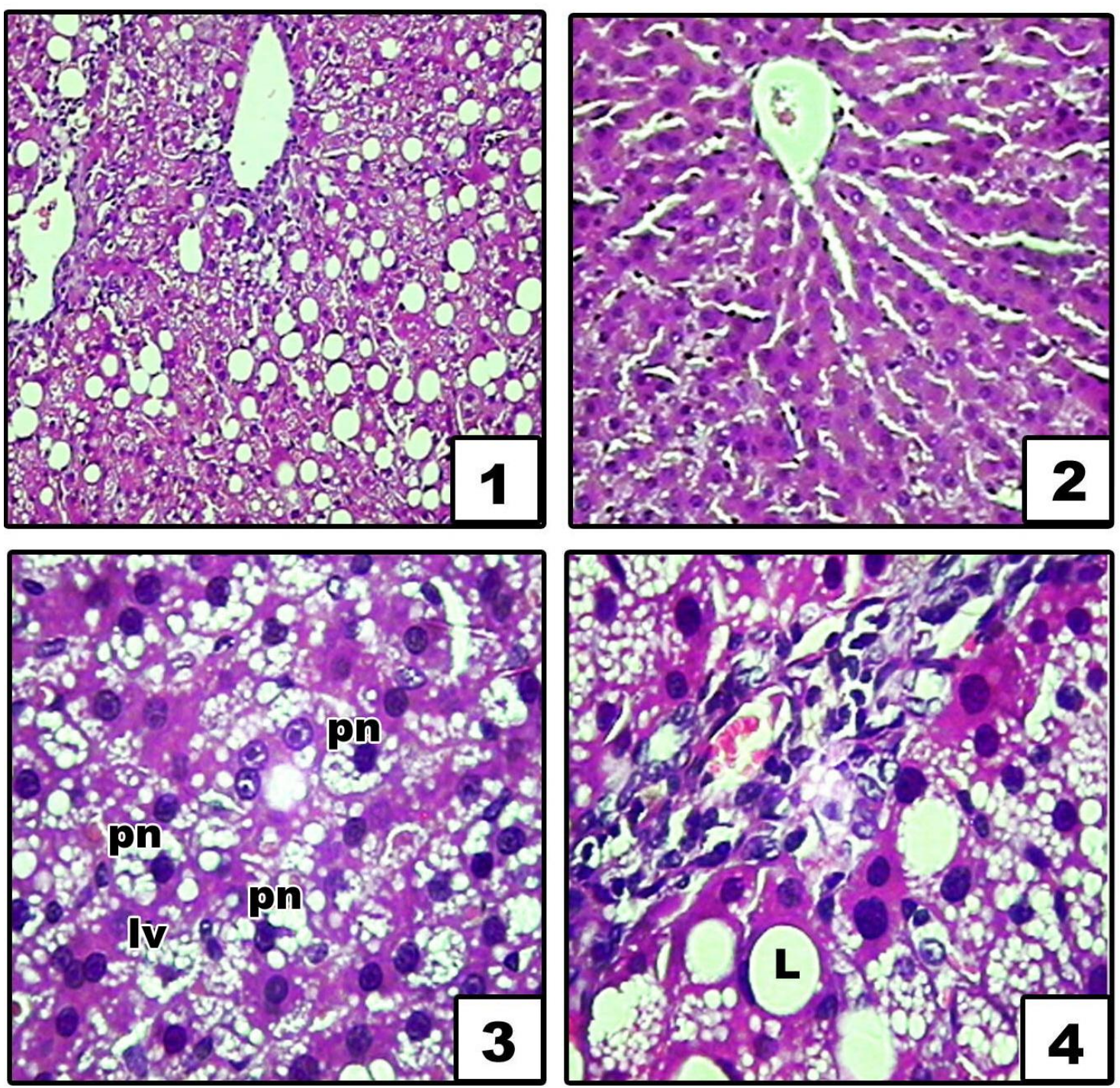

Fig.1. Section in the liver of control rat showing hepatic cells (h), Sinusoidal spaces (s) with Kupffer cells (k) and central vein (CV) (X150).

Fig.2. Section in the liver of hypercholesterolemic rat showing loss of the normal architecture of the liver with marked lipid infiltration (L), dilated sinusoids (s), central vein (CV)

$$
\text { (X150). }
$$

Fig.3. Section in the liver of hypercholesterolemic rat showing marked cloudily swelling hepatocytes with marked cytoplasmic vacuolations. Severe necrosis of hepatocytes, most of nuclei were pyknotic (pn) and lysis (ly)

Fig.4. Section in the liver of hypercholesterolemic rat showing marked proliferation of collagen fibers, inflammatory cellular infiltration, lipid droplets (L) and cytoplasmic vacuolations 

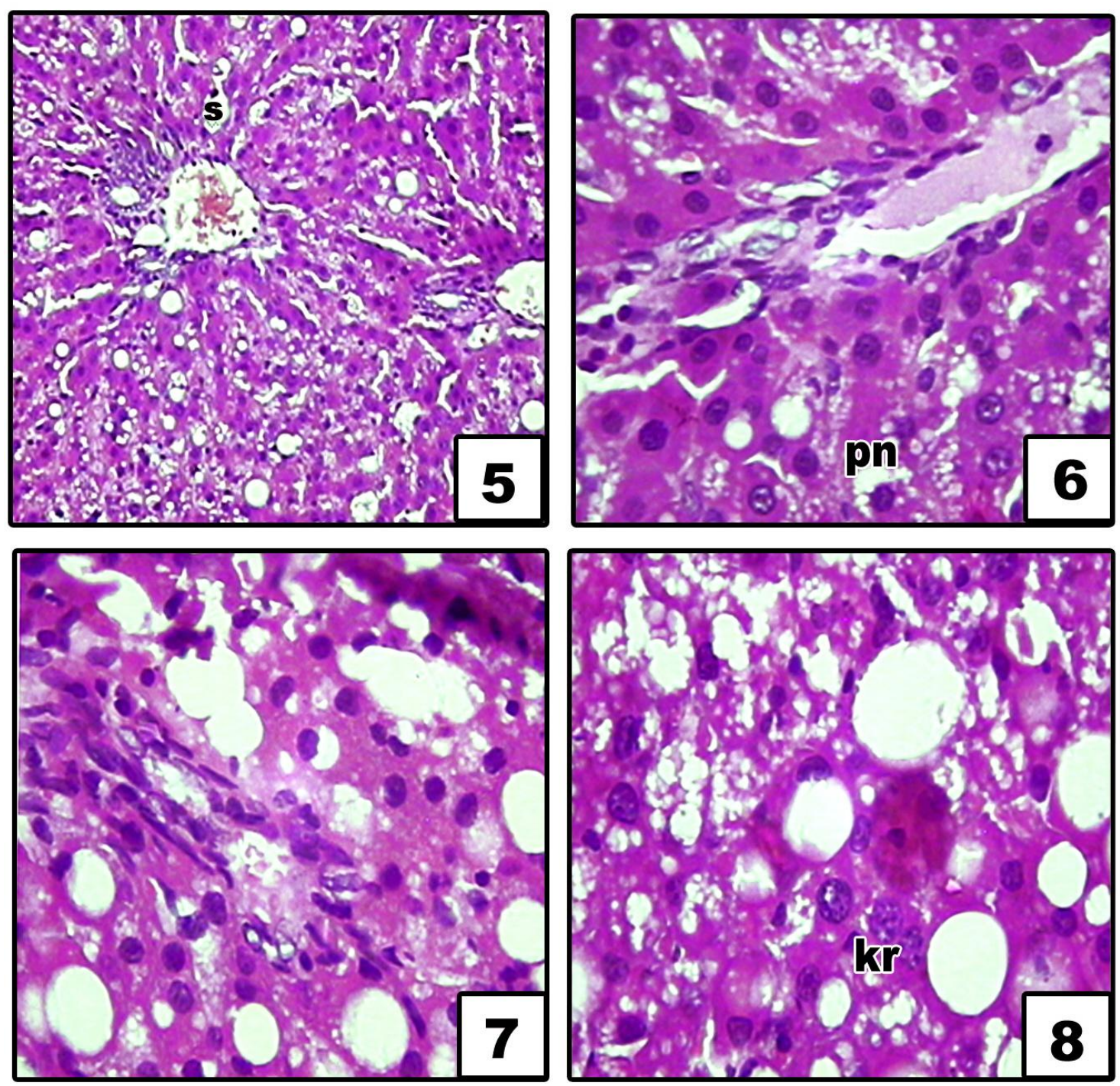

Fig.5. Section in the liver of oats-fed rat showed normal architecture of hepatocytes, reduction in fat accumulation, dilated sinusoids (s), reduction in fat accumulation (X150).

Fig.6. Section in the liver of oats-fed rat showed less inflammation, reduction in collagen content, inflammatory cellular infiltration and fat accumulation. Pyknotic nuclei (pn)

(X250).

Fig.7. Section in the liver of atorvastatin-treated rat showing fat accumulation, less inflammation and less fibrosis

(X250).

Fig.8. Section in the liver of atorvastatin-treated rat showing stages necrotic cells, karyorehxes (kr)

(X250). 


\section{Discussion}

Fatty liver is often linked to an excess of fat mass, and would result from an increase in total energy and carbohydrate intake in humans. There is evidence that food restriction and a lower body weight are accompanied by an improvement of fatty liver in obese adults and children (Eriksson et al., 1986). However, long-term maintenance of a low energy regimen by obese people is difficult; thus the discovery of nutrients that would ameliorate liver hepatic steatosis is of interest (Vajro et al., 1994) .

In the present study, atorvastatin treatment in rats induced significant reductions in serum plasma LDL; this finding is consistent with those previously reported by others (Kissebah et al.,1974; Dart et al., 1997; Bertolini et al.,1997; Bakker-Arkema et al.,1997; Durrington et al., 1998; McKenney et al., 1998). Guerin et al., 2000 reported that atorvastatin therapy $(10 \mathrm{mg} / \mathrm{d}$ for 6 weeks) in patients displaying a lipid phenotype characteristic of combined hyperlipidemia CHL induced significant reductions in both plasma total cholesterol and triglycerides $(31 \%$ and $27 \%$, respectively) and equally in very low density lipoproteins VLDL cholesterol $(-43 \%)$ and plasma low density lipoproteins LDL cholesterol (-36\%). They interpret their data to indicate that 2 independent but complementary mechanisms may be operative in the atorvastatin-induced reduction of atherogenic LDL levels in CHL: first, a significant degree of normalization of both the circulating levels and the quality of their key precursors, ie, VLDL1, and second, enhanced catabolism of the major LDL particle subclasses (ie, light, intermediate, and dense LDL) due to upregulation of hepatic LDL receptors.

Scientific studies support recommendations to increase dietary soluble fiber as part of hyperlipidemia treatment. Fibric acid derivatives act to inhibit the hepatic secretion of VLDL (Kissebah et al., 1974) and to promote triglyceride-rich lipoprotein catabolism through induction of lipoprotein lipase gene expression and stimulation of lipoprotein lipase activity (Heller and Harvengt, 1983).
Including water-soluble fiber in the diet was shown to be an additional, important component of cholesterol reduction efforts (Anderson et al., 1990). Oat gum, guar gum and pectin, all soluble fibers, have hypocholesterolemic effects in animals (Anderson et al., 1984, Matheson et al., 1995; Todd et al., 1990). The addition of beans, oat bran, locust bean gum, guar gum, psyllium or pectin to human diets reduces elevated cholesterol levels by $3-20 \%$, depending on study design (Judd and Truswell 1982; Zavoral et al., 1983; Anderson et al., 1984, 1991; Everson et al., 1992). Water-insoluble fiber does not affect cholesterol levels (Anderson et al., 1990, 1994; Jenkins et al., 1993).

Cara et al. (1992) included that oat bran lowers cholesterol more effectively than rice bran. Rice bran's fiber consists of a relatively low proportion of soluble fiber, $7-13 \%$ of its total dietary fiber compared with $40-47 \%$ in oat bran. The remainder is insoluble fiber. Other types of insoluble dietary fiber have failed repeatedly to reduce cholesterol levels (Katan 1987; Miettinen and Tarpila 1989; Kestin et al., 1990; Cara et al., 1992; Anderson et al., 1994).

Keenan et al., 1992 have demonstrated that niacin $(1500 \mathrm{mg} / \mathrm{d})$ and oat bran (56 g/d [2 oz/day]) have a synergistic effect on improving serum lipid levels, significant reductions ( $\mathrm{P}$ less than $.05)$ occurred for total cholesterol $(-10 \%)$ and low-density lipoprotein cholesterol ($16 \%)$. High-density lipoprotein cholesterol rose significantly at the end of the oat bran plus niacin phase, but returned to near baseline by the end of the study.

Oat bran contains soluble fibers, such as B-glucan, that increase bile acid excretion and thus decrease serum cholesterol. Significant reductions in serum LDLcholesterol concentrations when the $\beta$ glucan preparation from oat bran was given with a drink (Asp et al.,1983; Reihner et al.,1990). A possible mechanism of action for the cholesterol-lowering effect of Bglucan is decreased bile acid reabsorption caused by fiber binding or by an increased viscosity of intestinal contents (Axelson et 
al., 1988). Similarly, the present data illustrated the efficacy of oat in reduction of plasma LDL comparing to hypocholesterolemic drug, atorvastatin.

The mechanism by which soluble fiber reduces serum cholesterol is not definitively established. The most likely postulate is that intestinal bile salt adsorption by fiber prevents bile salt reabsorption with or without dietary cholesterol absorption (Ebihara and Schneeman 1989). This leads to increased bile salt synthesis (Everson et al., 1992; Matheson et al., 1995) and low-density lipoprotein (LDL) receptor upregulation and enhanced LDL catabolism, and there is evidence supporting this (Fernandez et al., 1995).

The antioxidative phytochemicals in grains, vegetables and fruits have received increased attention recently for their potential role in prevention of human diseases as well as in food quality improvement (Chu et al., 2002; Nandita and Rajini, 2004). Recent studies have suggested the role of phenolic compounds as the major source of natural antioxidants in foods of plant origin (Khalil and Darwish, 2005a,b). Oat (Avena sativa L.) is a source of many compounds that exhibit antioxidant activity. Vitamin E, phytic acid, significant quantities of phenolic compounds, and avenanthramides are the most abundant antioxidant in oat, flavonoids and sterols are also present (Mensink and Katan, 1992; Peterson, 2001).

The observed increase in the activity of the serum AST enzyme of hypercholesterolemic rats in the present study may be attributed to hyperlipidemia. Hyperlipidemia leads to injury of liver tissue so when cell membrane is damaged, these enzymes which are normally located in the cytosol, leak into the blood streams.

The present biochemical results exhibited significant reductions in serum LDL-cholesterol concentrations in oats-fed rats rather than atorvastatin-treated rats. The histopathological findings support these results. These improvement may attributed to the different radical scavenging of oat components that could reacts with radicals by donating protons (free radical quenching), radical addition, redox reaction (electron transfer) and radical combination (Yu et al., 2002).
The present study, however, confirms that the cereal grain oat may have potent beneficial health effects in reducing LDL cholesterol and should be included in the prudent diet of individuals with hyperlipidemia.

\section{References}

1. Alaupovic P, Heinonen $\mathbf{T}$, Shurzinske $\mathbf{L}$, Black DM (1997): Effect of a new HMGCoA reductase inhibitor, atorvastatin, on lipids, apolipoproteins and lipoprotein particles in patients with elevated serum cholesterol and triglyceride levels. Atherosclerosis.133:123-133.

2. Anderson J W, Deakins D A, Floore T L, Smith B M, Whitis S E (1990): Dietary fiber and coronary heart disease. Crit. Rev. Food Sci. Nutr. 29:95-147

3. Anderson J W, Jones A E, RiddellMason S (1994): Ten different dietary fibers have significantly different effects on serum and liver lipids of cholesterol-fed rats. J. Nutr. 124:78-83

4. Anderson J W, Story L, Sieling B, Chen W L, Petro M S, Story J (1984): Hypocholesterolemic effects of oat bran or bean intake for hypercholesterolemic men. Am. J. Clin. Nutr. 40:1146-1155

5. Asp NG, Johansson CG, Hallmer H, Siljeström M (1983): Rapid enzymatic assay of insoluble and soluble dietary fiber. J Agric Food Chem. 31:476-82

6. Axelson M, Aly A, Sjövall J ( 1988): Levels of 7 alpha-hydroxy-4-cholesten-3one in plasma reflect rates of bile acid synthesis in man. FEBS Lett. 239:324-8.

7. Bakker-Arkema RG, Davidson MH, Goldstein RJ, Davignon J, Isaacsohn JL, Weiss SR, Keilson LM, Brown WV, Miller VT, Shurzinske LJ, Black DM. (1996): Efficacy and safety of a new HMG-CoA reductase inhibitor, atorvastatin, in patients with hypertriglyceridemia. JAMA. 275:128-133.

8. Bell S, Goldman VM, Bistrian BR, Arnold AH, Ostroff G, Forse RA ( 1999): Effect of B-glucan from oats and yeast on serum lipids. Crit Rev Food Sci Nutr.39:189-202

9. Bertolini S, Bittolo Bon G, Campbell LM, Farnier M, Langan J, Mahla G, Pauciullo P, Sirtori C, Ergos F, Fayyad R, Nawrocki J ( 1997): Efficacy and safety of atorvastatin compared to pravastatin in patients with hypercholesterolemia. Atherosclerosis. 130:191-197.

10. Bourdon I, Yokoyama W, Davis $\mathbf{P}$ (1999) : Postprandial lipid, glucose, 
insulin, and cholecystokinin responses in men fed barley pasta enriched with Bglucan. Am. J. Clin Nutr, 69:55-63.

11. Braaten JT, Wood PJ, Scott FW, (1994): Oat ß-glucan reduces blood cholesterol concentration in hypercholesterolemic subjects. Eur. J. Clin. Nutr.,48:465-74

12. Brown L, Rosner B, Willett WW, Sacks FM. (1999): Cholesterol-lowering effects of dietary fiber: a meta-analysis. Am J Clin Nutr.69:30-42

13. Cara L, Dubois C, Borel P, Armand M, Senft M, Portugal H, Pauli A M, Bernard P M, Lairon D (1992): Effects of oat bran, rice bran, wheat fiber and wheat germ on portprandial lipemia in healthy adults. Amer. J. Clin. Nutr., 55:81-88

14. Chenhanyao $\mathrm{z}$ (2006): Atorvastatin right hyperlipidemia lipid-lowering efficacy of clinical observation. Channel Pharmacy., 6: 35-44.

15. Chu YF, Sun J, Wu X, Liu H (2002): Antioxidant and antiproliferative activities of common vegetables. J. Agricul. and Food Chem., 50: 6910-6916.

16. Cohen JC (1999): Contribution of cholesterol 7 alpha-hydroxylase to the regulation of lipoprotein metabolism. Curr Opin Lipidol., 10:303-7

17. Dart A, Jerums G, Nicholson G, d'Emden M, Hamilton-Craig I, Tallis G, Best J, West M, Sullivan D, Bracs P, Black D. (1997): A multicenter, doubleblind, one-year study comparing safety and efficacy of atorvastatin versus simvastatin in patients with hypercholesterolemia. Am J. Cardiol., 80:39-49

18. Davidson MH, Dugan LD, Burns JH, Bova J, Story K, Drennan KB. (1991). The hypocholesterolemic effects of $B$ glucan in oatmeal and oat bran. A dosecontrolled study. JAMA., 265:1833-9

19. Durrington PN, Mackness MI, Bhatnagar D, Julier K, Prais H, Arrol S, Morgan J, Wood GNI. (1998): Effects of two different fibric acid derivatives on lipoproteins, cholesteryl ester transfer, fibrinogen, plasminogen activator inhibitor and paraoxonase activity in type IIb hyperlipoproteinemia. Atherosclerosis., 138: 217-225.

20. Ebihara K, Schneeman B O (1989): Interaction of bile acids, phospholipids, cholesterol and triglyceride with dietary fibers in the small intestine of rats. J. Nutr., 119:1100-1106

21. Eriksson, S, Eriksson K F \& Bondesson, L (1986): Nonalcoholic steatohepatitis in obesity: a reversible condition. Acta. Med. Scand., 220:83-88.
22. Everson G T, Daggy B P, McKinley C, Story J (1992): Effects of psyllium hydrophilic mucilloid on LDL-cholesterol and bile acid synthesis in hyperch-olesterolemic men. J. Lipid Res., 33:1183-1192

23. Fernandez M L, Ruiz L R, Conde A K, Sun D-M, Erickson S. M., McNamara D J (1995): Psyllium reduces plasma LDL in guinea pigs by altering hepatic cholesterol homeostatsis. J. Lipid Res., 36:1128-1138

24. Food and Drug Administration (1996): Food labeling: health claims; oats and coronary heart disease. HHS. Proposed rule. Fed Regist. 61: 296-313.

25. Grundy SM, Ahrens EH Jr, Salen G ( 1971): Interruption of the enterohepatic circulation of bile acids in man: comparative effects of cholestyramine and ileal exclusion on cholesterol metabolism. J Lab Clin Med., 78:94-121

26. Guerin $\mathbf{M}$, Lassel T, Le Goff W, Farnier M.; John Chapman M. (2000) Action of Atorvastatin in Combined Hyperlipidemia. Preferential Reduction of Cholesteryl Ester Transfer From HDL to VLDL1 Particles. J. Arteriosclerosis, Thrombosis and Vascular Biol., 20:189-198.

27. Heller F, Harvengt C (1983) Effects of clofibrate, bezafibrate, fenofibrate and probucol on plasma lipolytic enzymes in normolipaemic subjects. Eur. J. Clin. Pharmacol., 25:57-63.

28. Jacobs L R (1983) Effects of dietary fiber on mucosal growth and cell proliferation in the small intestine of the rat: a comparison of oat bran, pectin, and guar with total fiber deprivation. Am. J. Clin. Nutr., 37: 954960.

29. Jenkins D , Wolever T, Rao A, Hegele R, Mitchell S, Ransom T, Boctor D (1993) Effect on blood lipids of very high intakes of fiber in diets low in saturated fat and cholesterol. Engl. J. Med., 329:21-26

30. Judd P and Truswell A (1982): Comparison of the effects of high and lowmethoxyl pectins on blood and faecal lipids in man. Br. J. Nutr., 48:451-458

31. Katan M B (1987): Direct and indirect effects of dietary fibre on plasma lipoproteins in man. Scand. J. Gastroenterol. $129: 218-222$.

32. Keenan J M, Wenz J B, Ripsin C M , Huang Z, McCaffrey D J (1992): A clinical trial of oat bran and niacin in the treatment of hyperlipidemia. J.Fam. Pract, . 34(3): 313-9

33. Kestin M, Moss R, Clifton P M, Nestel P J (1990): Comparative effects of three cereal brans on plasma lipids, blood 
pressure and glucose metabolism in mildly hypercholesterolemic men. Am. J. Clin. Nutr., 52:661-666

34. Khalil NS and Darwish GA (2005a): Antiradical properties of oat (Avena Sativa L.) flour extracts. Egypt. J. Biotechnol., 20,401-412

35. Khalil NS and Darwish GA (2005b): Levels of some selected antioxidants organic acids, aldehydes, alcohols and amides in oat (Avena Sativa L.) groats and hulls. Egypt. J. Biotechnol., 20: 474-483

36. Kirby RW, Anderson JW, Sieling B (1981): Oat-bran intake selectively lowers serum low-density lipoprotein cholesterol concentrations of hypercholesterolemic men. Am. J. Clin. Nutr., 34:824-9.

37. Kissebah AH, Adams PW, Harrigan P, Wynn V (1974): The mechanism of action of clofibrate and tetranicotinoylfructose (bradilan) on the kinetics of plasma free fatty acid and triglyceride transport in type IV and type V hypertriglyceridaemia. Eur. J. Clin. Invest., 4:163-174.

38. Li Z Q, Yuan S Ze R (2003): A small dose of atorvastatin treatment of hypercholesterolemia effect. J. Zhengzhou University, 6:41-50.

39. Marlett JA, Hosig KB, Vollendorf NW, Shinnick FL, Haack VS, Story JA (1994): Mechanism of serum cholesterol reduction by oat bran. J.Hepatol., 20:14507

40. Matheson H B, Colon I S, Story J A (1995): Cholesterol $7^{\beta}$-hydroxylase activity is increased by dietary modification with psyllium hydrocolloid, pectin, cholesterol and cholestyramine in rats. $J$. Nutr., 125:454-458

41. McKenney JM, McCormick LS, Weiss S, Koren M, Kafonek S, Black DM (1998): A randomized trial of the effects of atorvastatin and niacin in patients with combined hyperlipidemia or isolated hypertriglyceridemia. Am. J. Med.,104:137143.

42. Mensink RP, Katan MB (1992): Effect of dietary fatty acids on serum lipids and lipoproteins: a meta-analysis of 27 trials. Arterioscler Thromb.,12:911-9.

43. Miettinen T A, Tarpila S (1989): Serum lipids and cholesterol metabolism during guar gum, plantago ovata and high fibre treatments. Clin. Chim. Acta. 183:253-262

44. Miettinen TA (1979): Effects of neomycin alone and in combination with cholestyramine on serum cholesterol and fecal steroids in hypercholesterolemic subjects. $J$ Clin Invest., 64:1485-93
45. Moussavi Z, Plancke M O, Oliver P H Lesieur D, Prruchart J C and Sauzieres J (1989): Lipid lowering actions of 7(2-methylene-butyryl) -1,4-benzoxazin-3$(4 \mathrm{H})$-one derivatives in mice, rats and syrian hamasters. Clinica Chimica Acta., 180: $35-44$.

46. Nandita S and Rajini PS (2004): Free radical scavenging activity of an aqueous extract of potato peel. Food Chemistry., 85,611-616.

47. Nawrocki JW, Weiss SR, Davidson MH, Sprecher DL, Schwartz SL, Lupien PJ, Jones PH, Haber HE, Black DM. (1995): Reduction of LDL cholesterol by $25 \%$ to $60 \%$ in patients with primary hypercholesterolemia by atorvastatin, a new HMG-CoA reductase inhibitor. Arterioscler Thromb Vasc Biol. 15:678-682

48. Nicolosi R, Bell SJ, Bistrian BR, Greenberg I, Forse RA, Blackburn GL (1999): Plasma lipid changes after supplementation with B-glucan fiber from yeast. Am J Clin Nutr., 70:208-12.

49. Peterson DM (2001): Oat antioxidants. J.Sci., 33,115-129.

50. Reihner E, Angelin B, Rudling M, Ewerth S, Björkhem I, Einarsson K ( 1990): Regulation of hepatic cholesterol metabolism in humans: stimulatory effects of cholestyramine on HMG-CoA reductase activity and low density lipoprotein receptor expression in gallstone patients. $J$ Lipid Res., 31:2219-26.

51. Ripsin CM, Keenan JM, Jacobs DR (1992): Oat products and lipid lowering. A meta-analysis. JAMA, 267:3317-25.

52. Snedecor $G$ and Cochran W (1967): Statistical methods. Low State University Press. Ames. Iowa, 59-60.

53. Todd P A, Benfield P, Goa K L (1990): Guar gum: a review of its pharmacological properties, and use as a dietary adjunct in hpercholesterolaemia. Drugs., 39:917-928

54. Vajro P, Fontanelle A, Perna C, Orso G, Tedesco M \& De Vincenzo A (1994): Persistent hyperaminotransferasemia resolving after weight reduction in obese children. J. Pediatr. 125:239-241.

55. Yu L, Haley S, Perret J, Harris M, Wilson J and Quin M (2002): Free radical scavenging properties of weat extracts. J. Agric. Food Chem., 50: 1619-1624.

56. Zavoral J H, Hannan P, Stat M, Fields D J, Hanson M N, Frantz I D, Kuba K, Elmer P, Jacobs D R (1983): The hypolipidemic effect of locust bean gum food products in familial hypercholesterolemic adults and children. Am. J. Clin. Nutr., 38:285-294 
تأثير نخالة الثوفان مقارنة بعقار أتورفاستاتين في علاج ارتفاع الكوليسترول

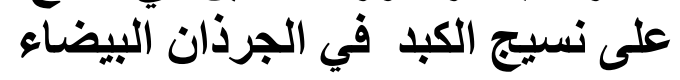

\section{ميسـاء محمد الراوي}

قسم الأحياء ـ كلية التربية الأقسام العلمية للبنات ـ مكة المكرمة

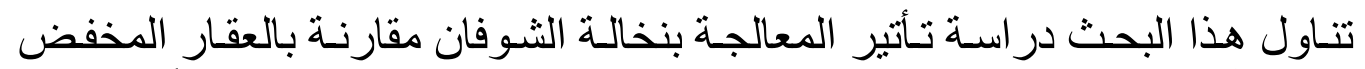

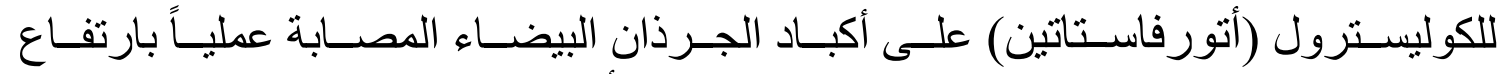

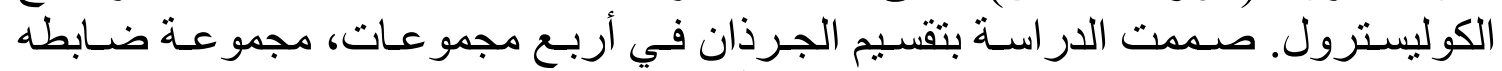

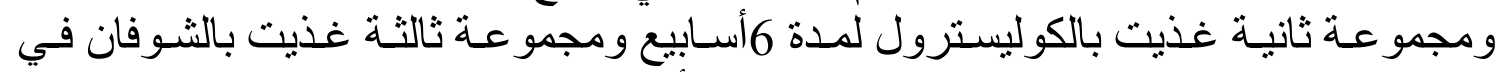

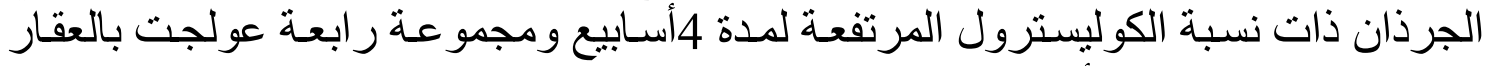

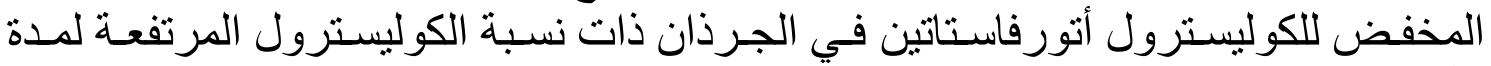

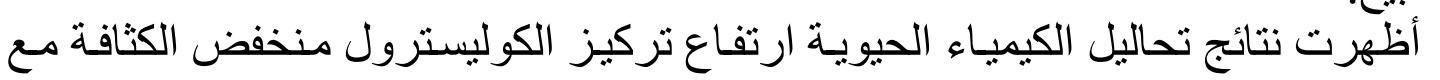

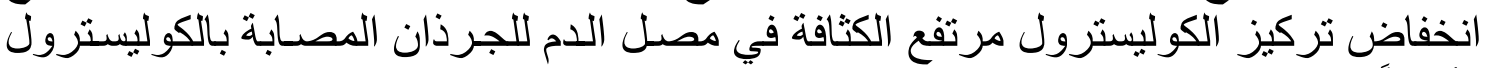

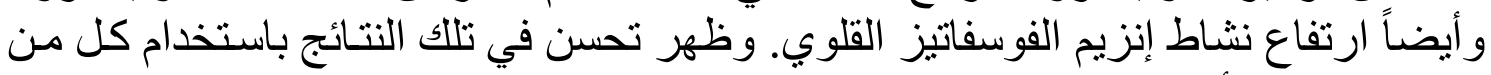

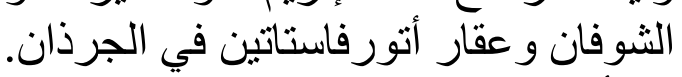

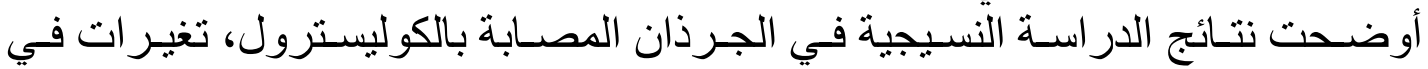

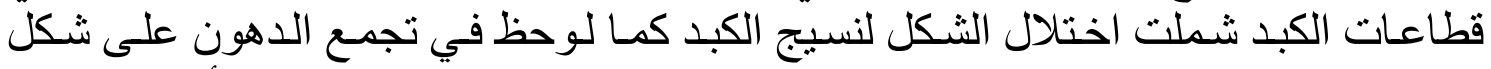

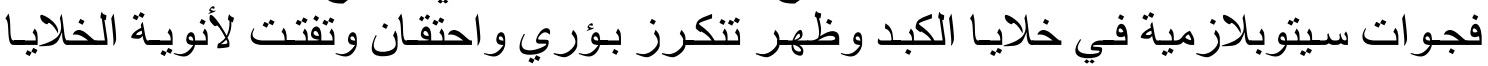

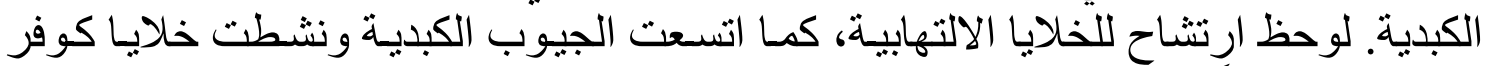

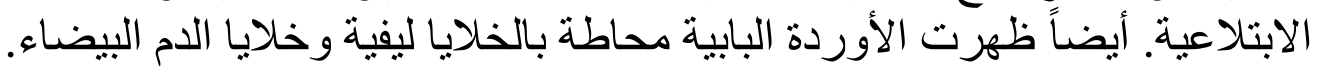

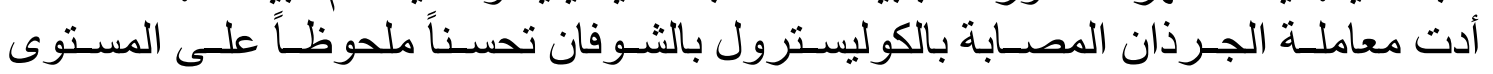

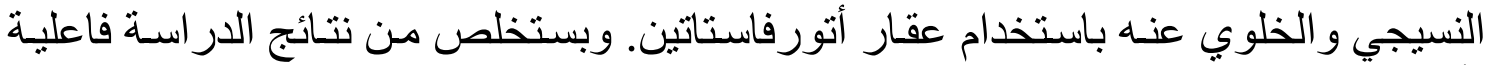

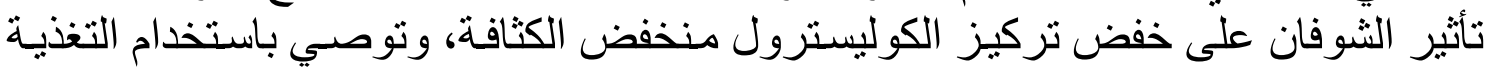
بالثوفان في المرضى المصابين بارتفاع الكوليسترول. 